\title{
ỬNG DỰG GIS KẾT HỢP KỸ THUẬT PHÂN CẤP THỨ BẬC AHP VÀ LÝ THYẾT MỜ TRONG VIỆC LỰA CHỌN VỊ TRÍ QUY HOẠCH CỤM CÔNG NGHIỆP TẠI HUYỆN HOÀI ĐỨC, THÀNH PHỐ HÀ NỘI
}

\author{
VŨ KHẮC HÙNG(1), ĐỒNG VŨ HÀ̀(1), DƯƠNG HOÀNG LONG ${ }^{(1)}$, \\ TRÀ̀ TH!̣ VÂN ANH(1), TRÀ̀N VĂN TUẤN ${ }^{(1)}$, LƯƠNG TH!̣ KIM DUNG(2) \\ ${ }^{(1)}$ Trường Đại học Khoa học Tụe nhiên, Đại học Quốc gia Hà Nội \\ ${ }^{(2)}$ Truò̀ng Cao đẳng Vĩnh Phúc
}

\section{Tóm tắt:}

Quá trình công nghiệp hóa, hiện đại hóa, trong đó xây dưng các khu, cụm công nghiệp đã góp phần làm cho kinh tế nước ta phát triển mạnh trong nhũng năm vìa qua. Tính đến hết năm 2020, toàn quốc có 968 cum công nghiệp được thành lập [8]. Tuy nhiên, hiện nay việc bố trí vị trí xây dựng các cưm công nghiệp tại các địa phương vìa đảm bảo về lợi ích kinh tế nhưng đồng thời cần đảm bảo về môi truờng còn nhiều khó khăn. Số cưm công nghiệp có biện pháp bảo vệ môi truờng, công trình xủ lý chất thải chi chiếm khoảng 19,3\%. Dưới góc độ nhà quy hoạch về đất đai, việc lựa chọn vị trí quy hoạch các đối tượng dễ gây tổn thuơng cho môi truờng nhu khu vực sản xuất công nghiệp là việc làm rất quan trọng. Sụ kết hợp giữa phương pháp phân tích thứ bậc AHP, lý thuyết mò̀ Fuzzy và công nghệ GIS giúp xác định vị trí thích hợp và đánh giá sụ hợ lý cho các vị trí quy hoạch. Nghiên cứu thực hiện tại huyện Hoài Đức, huyện ngoại thành Hà Nội là địa bàn có khá nhiều các cự công nghiệp, làng nghề sản xuất.

\section{Mở đầu}

Trong quá trình đổi mới ở Việt Nam, việc phát triển các khu, cụm công nghiệp là động lực thúc đẩy sự nghiệp công nghiệp hóa, hiện đại hóa đất nước. Từ năm 1991, song hành cùng với quá trình đổi mới và mở cửa nền kinh tế, Đảng và Nhà nước đã chủ trương hình thành các Khu công nghiệp với ý nghĩa là các trung tâm sản xuất công nghiệp, dịch vụ có kết cấu hạ tầng đồng bộ, hiện đại. Khác với các quy hoạch các khu công nghiệp, các cụm công nghiệp có quy mô vừa và nhỏ hơn (không quá 75 ha), hoạt động chủ yếu trong lĩnh vực sản xuất công nghiệp tiểu thủ công nghiệp, cơ sở dịch vụ phục vụ sản xuất [9]. Tùy thuộc vào nhu cầu và lợi thế sản xuất của từng địa phương, UBND cấp tỉnh, thành phố trực thuộc trung ương quyết định thành lập cựm công nghiệp. Tính đến hết năm 2020, toàn quốc có 968 cụm công nghiệp được thành lập với tổng diện tích trên 30.912 ha [8]. Tuy nhiên, trong đó chỉ có 141 cụm công nghiệp có hệ thống xử lý nước thải tập trung và đang hoạt động. Điều này đồng nghĩa với mức độ ô nhiễm của các cụm công nghiệp còn lại ảnh hưởng đến môi trường xung quanh là rất lớn.

Huyện Hoài Đức là một huyện ngoại thành Hà Nội, với định hướng phát triển thành quận đến năm 2025, huyện đã có nhiều phát triển nổi bật trong những năm vừa qua. Đến cuối năm 2020, mặc dù ảnh hưởng bởi dịch Covid-19 nhưng kinh tế của huyện tiếp tục tăng trưởng $k h a ́$ (tăng 10,74\% so cùng kỳ), cơ cấu kinh tế chuyển dịch đúng hướng, thương mại - dịch vụ 54,04\%, công nghiệp - xây dựng 41,26\%, nông nghiệp $4,7 \%$ [8]. Huyện cũng là địa phương nổi tiếng với các cụm công nghiệp như Cụm công nghiệp Cầu Nổi (xã Vân Canh, Hoài Đức) và cự công nghiệp Trường An (xã An Khánh, Hoài Đức)...và đặc biệt là sự phát triển của các làng nghề sản xuất như làng nghề chế biến nông sản thực phẩm 
Dương Liễu, làng nghề dệt và sản xuât bánh kẹo La Phù... Những cụm công nghiệp mang lại nhiều việc làm cho người dân địa phương, giúp phát triển kinh tế địa phương nhưng đồng thời cũng gây ô nhiễm môi trường trầm trọng tại các khu vực sản xuất. Trong khi cơ sở hạ tầng về xử lý chất thải của các khu vực này chưa được đáp ứng khiến cho cuộc sống của người dân tại gần các khu sản xuất công nghiệp chịu ảnh hưởng nặng nề. Đây cũng là một trong năm tiêu chí huyện Hoài Đức chưa hoàn thành để đạt chỉ tiêu lên quận.

Hiện nay, Hoài Đức có ba dự án xây dựng các nhà máy xử lý nước thải. Tuy nhiên, hiện chỉ có Nhà máy Xử lý nước thải Cầu Ngà (xã Dương Liê̂u) công suất 20 nghìn $\mathrm{m}^{3} /$ ngày đi vào hoạt động. Nhà máy này mới xử lý được một phần nước thải cho các hộ sản xuất trong đê của ba xã Dương Liễu, Cát Quế và Minh Khai, còn nước thải khu vực ngoài đê sông Đáy (khoảng 3.000 hộ dân) chưa được xử lý nên tình trạng ô nhiễm môi trường vẫn diễn ra.

Trong công tác quản lý đất đai, việc phát hiện và xử lý vi phạm về ô nhiễm môi trường là vô cùng quan trọng. Trong xây dựng các khu cụm công nghiệp, việc lập quy hoạch sử dụng đất hợp lý được coi là vấn đề then chốt trong điều phối sử dụng đất hài hòa, vừa đảm bảo phát triển kinh tế vừa đảm bảo tránh gây ảnh hưởng đến môi trường xung quanh. Trong những năm gần đây, với sự phát triển của hệ thống thông tin địa lý (GIS), các bài toán tối ưu hỗ trợ cho việc lập quy hoạch sử dụng đất được quan tâm bởi nhiều chuyên gia quy hoạch. Trong đó, sự kết hợp của nền tảng GIS và phương pháp phân tích thứ bậc AHP, lý thuyết Fuzzy logic mang lại kết quả hữu ích và là cơ sở cho việc xác định các vị trí thích hợp cho quy hoạch sử dụng đất.

Trên thế giới, nghiên cứu về lựa chọn vị trí thích hợp cho việc quy hoạch mục đích sử dụng đất sản xuất công nghiệp ngày càng phát triển. Đặc biệt, với thế mạnh của công nghệ GIS, kết hợp cùng một số lý thuyết như phân cấp đa chỉ tiêu, lý thuyết mờ... các nghiên cứu này đã mang lại hiệu quả rõ rệt. Bằng việc áp dụng Hệ thống thông tin địa lý GIS và các công cụ ra quyết định đa chỉ tiêu (MCDM), nghiên cứu của Steven Kuba Nuhu và cộng sự, đã hỗ trợ việc lập và đưa ra các vị trí lựa chọn điểm quy hoạch khu công nghiệp sinh thái tại Iran và Trung Quốc [4]. Trong nghiên cứu của Aleksandar Rikalovic đã ứng dụng GIS kết hợp cùng các hệ thống ra quyết định (DSS) và phương pháp phân tích đa chỉ tiêu (MDCM), đưa ra một quy trình hỗ trợ quyết định vị trí không gian quy hoạch các địa điểm công nghiệp tại Vojvodina, Serbia [6]. Sự phát triển của lý thuyết mờ Fuzzy logic đã mang lại kết quả chính xác hơn khi kết hợp với kỹ thuật phân cấp thứ bậc AHP. Lý thuyết này đã làm giảm thiểu độ thiếu rõ ràng trong việc đưa ra ý kiến của chuyên gia. Nghiên cứu về địa chấn đối với vùng Nam Tứ Xuyên, Trung Quốc với việc sử dụng kết hợp các phương pháp EntropyFuzzy-AHP đã mang lại kết quả là mức độ ảnh hưởng của các hoạt động con người và tự nhiên trong việc tạo ra địa chấn tại khu vực [4]. Nhằm giảm thiểu sự không rõ ràng khi sử dụng phương pháp AHP, Bhanu Chander Balusa đã kết hợp với lý thuyết mờ trong việc lựa chọn phương pháp khai thác kim loại dưới lòng đất [1].

Tại Việt Nam, ứng dụng GIS kết hợp AHP và lý thuyết mờ được hiện thực hóa tại nhiều nghiên cứu ở các lĩnh vực khác nhau. Trong quy hoạch sử dụng đất, nghiên cứu của Nguyễn Xuân Linh và cộng sự về sự kết hợp giữa GIS, lý thuyết mờ và phương pháp phân tích đa chỉ tiêu đã đưa ra vị trí tối ưu cho việc quy hoạch mục đích sử dụng đất bãi chôn lấp chất thải rắn sinh hoạt tại huyện Hưng Hà, Thái Bình [11]. Thông qua GIS và phương pháp phân cấp thứ bậc mờ, nghiên cứu của Nguyễn Văn Lợi đã xác định địa điểm thích hợp trồng quế bản địa ở Trà Bồng, Quảng Ngãi [10]. Kết quả nghiên cứu mang lại ý nghĩa to lớn với người dân trồng quế tại Trà Bồng.

\section{Khu vực và phương pháp nghiên cứu}

\subsection{Khu vưc nghiên cứu}

Huyện Hoài Đức thuộc vùng đồng bằng sông Hồng với tổng diện tích đất tự nhiên là 8.246 ha, huyện nằm cách trung tâm thủ đô Hà Nội 16 
km... Vị trí địa lý của huyện phía bắc giáp huyện Đan Phượng, Phúc Thọ; Phía Tây giáp huyện Quốc Oai, Phúc Thọ; Phía nam giáp huyện Chương Mỹ và quận Hà Đông; Phía đông giáp các quận Hà Đông, Nam Từ Liêm [12].

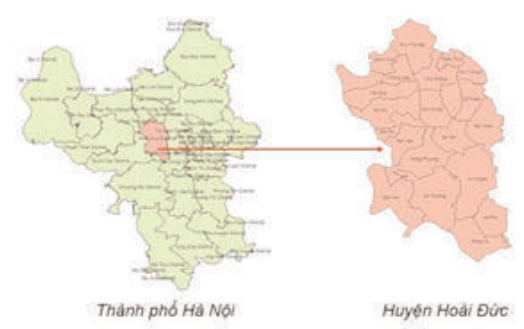

Hình 1: So đồ vị trí huyện Hoài Đức

Hoài Đức có quỹ đất thuận lợi cho phát triển các khu đô thị, song cơ cấu sử dụng đất hiện nay vẫn chưa hợp lý. Cơ cấu kinh tế của huyện trong những năm gần đây cho thấy tỷ lệ các ngành công nghiệp, xây dựng, thương mại và dịch vụ ngày càng tăng. Do vậy, việc phân bổ quỹ đất hợp lý cho các ngành công nghiệp, tiểu thủ công nghiệp, thương mại và dịch vụ... chiếm tỷ lệ lớn. Phần lớn sẽ vào đất đang được sử dụng chủ yếu là đất nông nghiệp [12].

Vì vậy cần sử dụng đất hợp lý, tiết kiệm, đảm bảo sử dụng đất đúng mục đích, có hiệu quả và gắn liền với việc bảo vệ môi trường sinh thái, bền vững. Đồng thời đầu tư cải tạo, khai thác đất chưa sử dụng và thực hiện tốt các biện pháp thâm canh tăng vụ, nâng cao năng suất cây trồng, chất lượng sản phẩm, nâng cao hiệu quả sử dụng đất.

Với Quy hoạch chung xây dựng Thủ đô Hà Nội đến năm 2030 và tầm nhìn đến năm 2050 đã được Thủ tướng Chính phủ phê duyệt tại Quyết định số 1259/QĐ-TTg, huyện Hoài Đức nằm trong khu đô thị trung tâm mở rộng của thủ đô Hà Nội.

\subsection{Phưong pháp nghiên cúu}

Phương pháp AHP được ứng dụng khá phổ biến ở các lĩnh vực nghiên cứu nhằm định lượng hóa các chỉ tiêu. Tuy nhiên AHP cũng có hạn chế vì chưa thể giải quyết bài toán kết hợp giữa sự không chắc chắn và không chính xác trong ý kiến đánh giá của các chuyên gia để chuyển sang thành các con số chính xác khi xác định định trọng số. Vì vậy, giải pháp kết hợp giữa kỹ thuật tính trọng số $\mathrm{AHP}$ và lý thuyết mờ (viết tắt là FAHP) trong xác định trọng số cho mô hình giúp kết quả chính xác hơn.

\subsubsection{Phuoong pháp phân tích thứ bậc (AHP)}

Quá trình phân tích phân cấp (Analytical hierarchy process - AHP) được phát triển bởi Thomas L. Saaty từ những năm 1980 là một trong số kĩ thuật tính trọng số. AHP có thể giúp xác định và đánh giá các tiêu chí thúc đẩy việc ra quyết định nhanh hơn, chính xác hơn. Một quy trình AHP tiến hành dựa trên việc so sánh các tiêu chí với nhau sau đó kết hợp lại để đưa ra phương án tốt nhất [3].

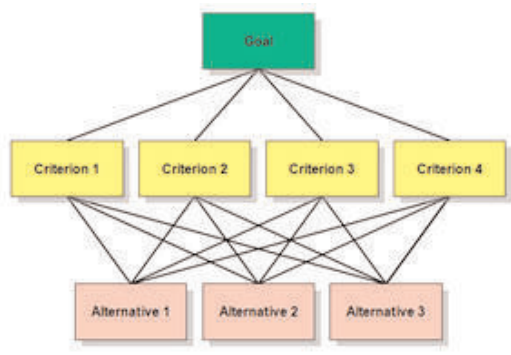

\section{Hình 2: Vi du về Hệ thống phân cấp chỉ tiêu}

AHP là một kỹ thuật hỗ trợ cho việc tạo ra quyết định, nó tỏ ra có hiệu quả khi trong các nhóm làm việc, cung cấp một cách tổng quan về thứ tự sắp xếp của các chỉ tiêu, lựa chọn trong một nhóm chỉ tiêu, từ đó đưa ra được quyết định cuối cùng hợp lý nhất. Nó giúp cân nhắc và đo lường các yếu tố cả về chủ quan và khách quan, tạo nên một cơ chế hữu dụng để đảm bảo tính nhất quán trong việc đánh giá, đo lường các giải pháp và các đề xuất được đưa ra trong nhóm làm việc.

Quy trình AHP được dựa trên một loạt các cặp chỉ tiêu so sánh với nhau, sau đó kết hợp lại và cho ra lựa chọn tối ưu nhất. Có thể khái quát thành các bước sau:

Bước 1: Xác định các phương án có thể xảy ra và các tiêu chí ảnh hưởng đến việc ra quyết 
định.

Bước 2: Đối với mỗi chỉ tiêu của mỗi nhóm tiêu chí, người ra quyết định hay các chuyên gia sẽ thể hiện ý kiến của mình về tầm quan trọng của chúng so với nhau dưới dạng một phân số có giá trị từ $1 / 9$ đến 9 .

Bước 3: Tính toán trọng số hay mức độ quan trọng của các chỉ tiêu dưới dạng các ma trận sau khi tham khảo ý kiến chuyên gia.

Bước 4: Tính tỷ số nhất quán dữ liệu $\mathrm{CR}$.

\subsubsection{Lý thuyết mò̀ Fuzzy logic}

Lý thuyết tập mờ được tác giả Zadeh giới thiệu năm 1965 nhằm giải quyết những vấn đề có tính chất không chắc chắn do sự thiếu chính xác hoặc thiếu rõ ràng [5].

Khái niệm “Tập hợp mờ” (Fuzzy Set) được sử dụng đáp ứng nhu cầu biểu diễn những nhận định thiếu chính xác. Trong lý thuyết tập hợp cổ điển (Crisp set), quan hệ thành viên của các phần tử đối với một tập hợp được đánh giá theo kiểu nhị phân một cách rõ ràng, tức mỗi phần tử của vũ trụ tham chiếu $X$ là chắc chắn thuộc tập $\mathrm{M}$ hoặc chắc chắn không thuộc tập $\mathrm{M}$. Hàm thành viên để đánh giá một phần tử có thuộc tập $\mathrm{M}$ hay không được biểu thị như sau:

$$
\forall x \in X, \mu_{M}(x)=\left\{\begin{array}{lll}
1 & \text { nếu } x & \in M \\
0 & \text { nếu } x & \notin M
\end{array}\right.
$$

Nhằm giải quyết sự thiếu chắc chắn trong tập dữ liệu, lý thuyết tập mờ cho phép đánh giá nhiều mức độ khác nhau về khả năng một phần tử có thể thuộc về một tập hợp. Tập mờ có thể được định nghĩa như sau: Xét $X$ là tập hợp gồm các phần tử. Tập mờ là một tập hợp được biểu diễn dưới dạng một hàm thành viên $\mu_{M}(x)$ thể hiện khả năng để thuộc vào tập $\mathrm{M}$. Giá trị biểu diễn mức độ thành viên của một phần tử nằm trong khoảng từ 0 tới 1 . Nếu $\mu_{M}(x)=0$ có nghĩa phần tử hoàn toàn không thuộc tập $M$ và ngược lại nếu $\mu_{M}(x)=1$ có nghĩa phần tử hoàn toàn thuộc tập $\mathrm{M}[2,7]$.

\subsubsection{Quy trình kết hơp GIS, AHP và Fuzzy}

logic trong lựa chọn và đánh giá sủ dụng đất cưm công nghiệp

Qua quá trình nghiên cứu tài liệu và thử nghiệm, nghiên cứu đề xuất quy trình ứng dụng GIS và FAHP gồm 8 bước.

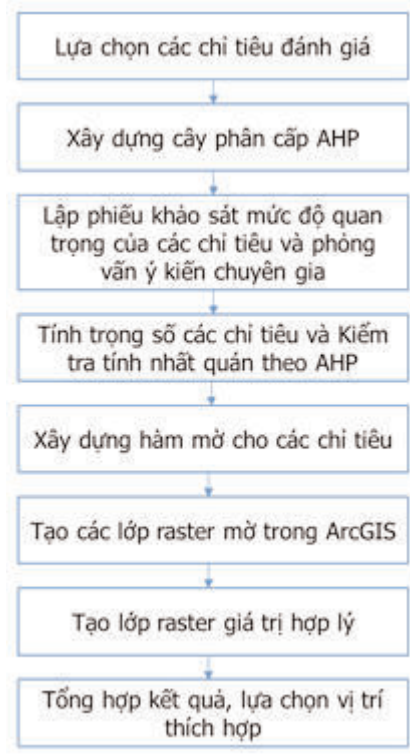

Hình 3: Quy trình úng dụng GIS, AHP và Fuzzy logic trong lưa chọn vị trí quy hoạch cum công nghiẹp

Phần mềm GIS được lựa chọn để biên tập, xử lý dữ liệu là ArcGIS, đây là một phần mềm mã nguồn mở với nhiều công cụ hữu ích trong việc phân tích không gian các đối tượng bản đồ.

\section{Kết quả nghiên cứu và thảo luận}

\subsection{Lưa chọn chỉ tiêu đầu vào}

Các chỉ tiêu được lựa chọn thông qua quá trình nghiên cứu Quy chuẩn xây dựng Việt Nam số 01:2019/BXD, Tiêu chuẩn Việt Nam số 44491997. Tuy nhiên, để bộ chỉ tiêu được đa dạng và chính xác hơn, nghiên cứu đã tham khảo thêm ý kiến của chuyên gia và các tài liệu liên quan khác.

Qua quá trình khảo sát, các dự án cụm công nghiệp ở Hoài Đức được xếp hạng mức độ độc hại loại 3 , tương ứng với Các nhà máy chế biến lương thực, thực phẩm, chế biến gỗ... 
Bảng 1: Các tiêu chí sủ dụng để lựa chọn vị trí thich hơp quy hoạch cụm công nghiệp

\begin{tabular}{|c|c|c|}
\hline $\begin{array}{l}\text { Nhóm } \\
\text { tiêu chí }\end{array}$ & Tiêu chí & Y nghìa \\
\hline \multirow{4}{*}{$\begin{array}{c}\text { I. Kinh } \\
\text { tế }\end{array}$} & $\begin{array}{l}\text { 1. Khoảng } \\
\text { cách tớ } \\
\text { aường giao } \\
\text { thông chinh } \\
\text { (cao tồc, } \\
\text { quốc lộ, tịnh } \\
\text { lộ, đường } \\
\text { săt) }\end{array}$ & 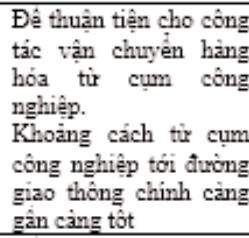 \\
\hline & $\begin{array}{l}\text { 2. Hiện trang } \\
\text { sự dựng đầt }\end{array}$ & 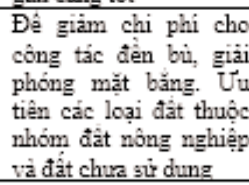 \\
\hline & $\begin{array}{l}\text { 3. Khoảng } \\
\text { cách đền } \\
\text { cự cồng } \\
\text { nghiệp đã có }\end{array}$ & 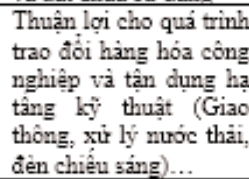 \\
\hline & $\begin{array}{l}\text { 4. Khoàng } \\
\text { cách tời các } \\
\text { công trinh } \\
\text { cung cầ } \\
\text { năng luơong }\end{array}$ & $\begin{array}{l}\text { Giảm thiêu chi phi } \\
\text { cung xây dựg cho } \\
\text { cưm công nghiẹp } \\
\text { Theo } \\
4449: 1987\end{array}$ \\
\hline \multirow{5}{*}{$\begin{array}{l}\text { II. Môi } \\
\text { trường }\end{array}$} & $\begin{array}{l}\text { 1. Khoàng } \\
\text { cách đến khu } \\
\text { đât ó }\end{array}$ & $\begin{array}{l}\text { Cách li phù hợ với } \\
\text { mưc đọ độc hại cúa } \\
\text { loại hinh cưm công } \\
\text { nghiẹp } \\
\text { Theo } \\
4449: 1987\end{array}$ \\
\hline & $\begin{array}{l}\text { 2. Khoàng } \\
\text { cách đấn khu } \\
\text { di tich }\end{array}$ & $\begin{array}{l}\text { Tăng tối đa khoảng } \\
\text { cách đến các khu di } \\
\text { tich. }\end{array}$ \\
\hline & $\begin{array}{l}\text { 3. Khoảng } \\
\text { cách đến khu } \\
\text { sân xuất } \\
\text { nông nghiệp }\end{array}$ & $\begin{array}{l}\text { Giảm thiều ô nhiểm tợi } \\
\text { các khu vực sản xuất } \\
\text { nông nghiệp }\end{array}$ \\
\hline & $\begin{array}{l}\text { 4. Khoảng } \\
\text { cách đền } \\
\text { nguốn nước } \\
\text { mặt }\end{array}$ & $\begin{array}{l}\text { Giảm thiểu ô nhiễm } \\
\text { đền nguôn nước mặt }\end{array}$ \\
\hline & $\begin{array}{l}\text { 5. Khoàng } \\
\text { cách đền bâii } \\
\text { rác, xừ lý } \\
\text { chầt thải }\end{array}$ & $\begin{array}{l}\text { Thuân lợi cho công tác } \\
\text { vận chuyển rác thai } \\
\text { cống nghiệp }\end{array}$ \\
\hline
\end{tabular}

Tùy thuộc vào mức độ độc hại của loại hình sản xuất, các cụm công nghiệp có thể bố trí đan xen hoặc cách li so với khu dân cư để tránh gây ô nhiễm cho môi trường xung quanh [9].

\subsection{Xác định trọng số cho các chỉ tiêu}

Sau khi tham khảo ý kiến 22 chuyên gia, nghiên cứu tiến hành xác định trọng số cho từng chỉ tiêu theo các bước ở mục 2.2.1. Sau khi có bảng ma trận dữ liệu ý kiến chuyên gia, nghiên cứu tiến hành chuẩn hóa ma trận và tính trọng số cho các chỉ tiêu.

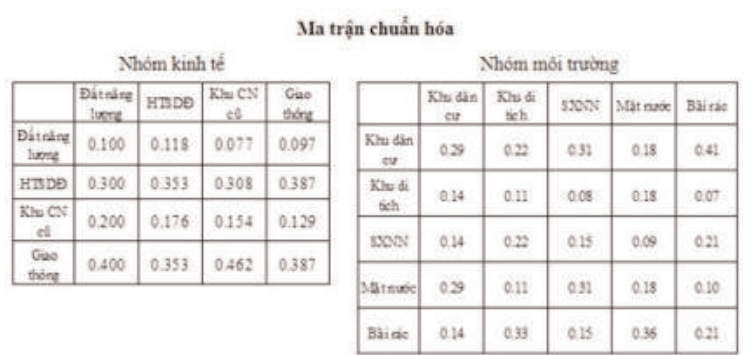

Hình 4: Ma trận chuấn hóa các chỉ tiêu

Để trọng số các chỉ tiêu được chấp nhận, phải đảm bảo tỷ số nhất quán (CR) luôn nhỏ hơn 0.1 (giá trị thể hiện độ nhất quán trong ý kiến của chuyên gia).

Kết quả xác định trọng số theo phương pháp AHP được thể hiện ở bảng 2:

Bảng 2: Trọng số của các chỉ tiêu lựa chọn vị trí quy hoạch cum công nghiẹp

\begin{tabular}{|c|l|c|}
\hline \multirow{2}{*}{ Nhóm } & \multicolumn{1}{|c|}{ Chỉ tiêu } & $\begin{array}{c}\text { Trọng số } \\
\text { chỉ tiêu }\end{array}$ \\
\hline \multirow{4}{*}{ Kinh tế } & Giao thông & 0.200 \\
\cline { 2 - 3 } & HTSDĐ & 0.169 \\
\cline { 2 - 3 } & Khu CN đã có & 0.083 \\
\cline { 2 - 3 } & Khu năng lượng & 0.049 \\
\hline \multirow{3}{*}{$\begin{array}{c}\text { Môi } \\
\text { trường }\end{array}$} & Khu dân cư & 0.140 \\
\cline { 2 - 3 } & Khu di tích & 0.060 \\
\cline { 2 - 3 } & Khu sàn xuất nông nghiệp & 0.080 \\
\cline { 2 - 3 } & Nguồn nước mặt & 0.100 \\
\cline { 2 - 3 } & Bãi rác & 0.120 \\
\hline \multicolumn{2}{|c|}{ Tổng } & 1.00 \\
\hline
\end{tabular}

Các chỉ tiêu được lựa chọn tương ứng với các chỉ tiêu mục 3.1.

\subsection{Xây dưng các hàm mờ cho các chỉ tiêu}

Các chỉ tiêu sau khi được tính trọng số bằng AHP sẽ được phân khoảng và tính điểm theo lý thuyết mờ. Cơ sở cho việc phân khoảng và xây dựng hàm mở cho các chỉ tiêu được dựa trên việc tham khảo ý kiến chuyên gia kết hợp cùng nghiên cứu các văn bản quy định, tài liệu liên quan.

Để xác định các hàm thành viên, đầu tiên, nghiên cứu tiến hành phân khoảng giá trị cho các yếu tố ảnh hưởng. Tiếp theo, căn cứ theo khoảng giá trị đã phân chia để vẽ đồ thị nhằm trực quan hóa các khoảng giá trị. Qua đó, các hàm thành viên sẽ được thiết lập cho phù hợp. 
Các hàm thành viên và đồ thị của các chỉ tiêu được thể hiện ở bảng dưới đây: (Xem bảng 3)

3.4. Xây dưng các lóp Raster thành phần và lớp Raster giá trị hợp lý

Dữ liệu không gian tại huyện Hoài Đức được sử dụng để xác định các vị trí hợp lý quy hoạch cụm công nghiệp là bản đồ hiện trạng sử dụng đất năm 2020. Sau quá trình chuẩn hóa dữ liệu bản đồ, tạo các lớp raster khoảng cách cho các chỉ tiêu, nghiên cứu tiến hành tạo các lớp raster mờ dựa trên các hàm mờ đã thiết lập ở phần trên. Riêng dữ liệu lớp hiện trạng sử dụng đất được phân loại theo các nhóm sử dụng đất và cho điểm theo ý kiến của chuyên gia, sau đó tiến hành chuyền từ dữ liệu dạng Vector sang Raster. (Xem hinh 5)

Mỗi lớp dữ liệu thành phần có trọng số (hay mức độ quan trọng) đã tính bằng phương pháp
AHP ở trên. Vì vậy, lớp raster giá trị hợp lý sẽ được xác định bằng tổng của điểm số từng lớp raster thành phần nhân với trọng số của chúng.

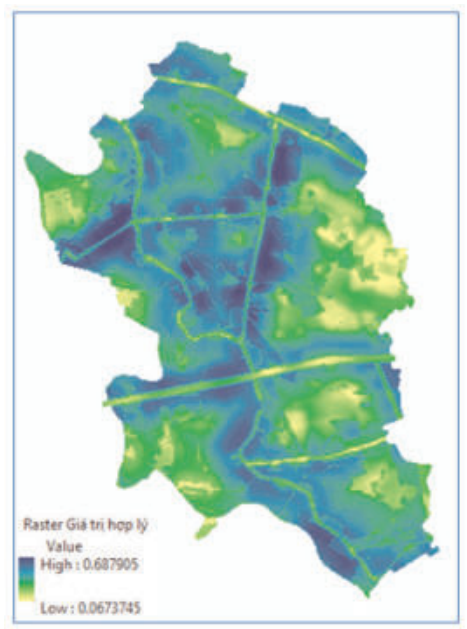

Hình 6: Lóp raster giá trị hơp lý quy hoạch cưm công nghiẹp

Bảng 3: Hàm thành viên và đồ thị của các chỉ tiêu

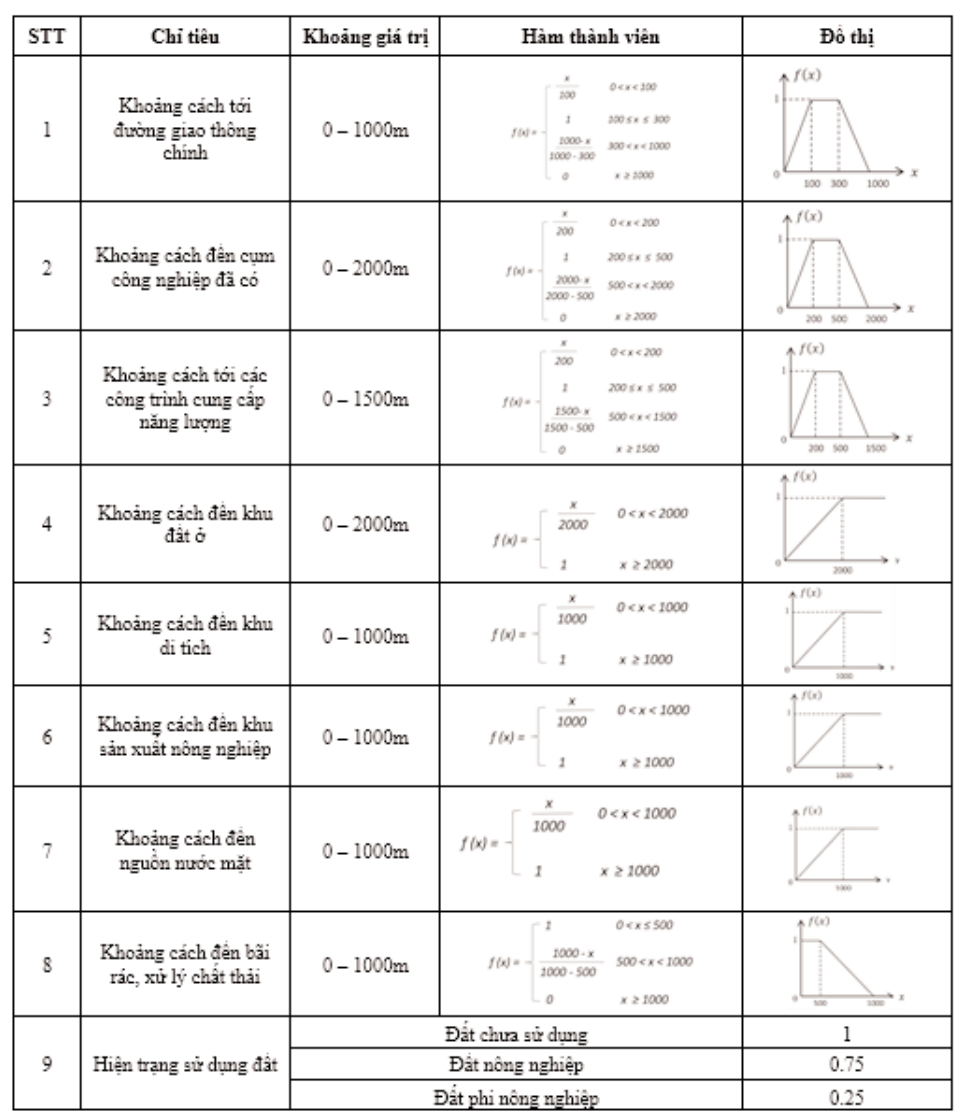




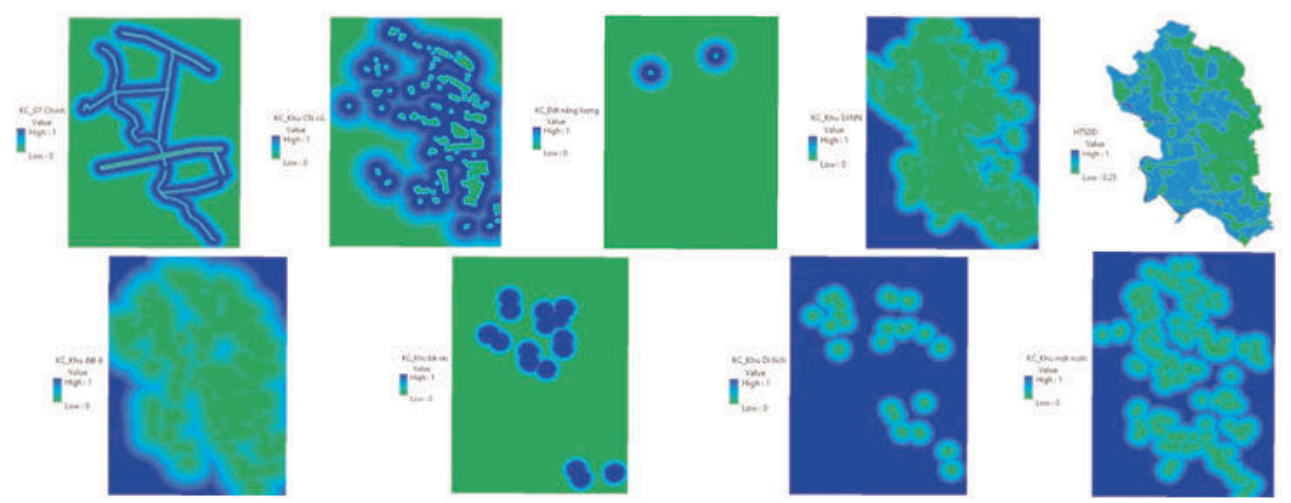

Hình 5: Các lớp raster được phân khoảng và tính điểm theo lý thuyết mò̀

Lớp dữ liệu giá trị hợp lý được thống kê mô tả như bảng bên dưới. Qua đó, nghiên cứu xác định ngưỡng điểm chuẩn $\mathrm{X}=0.313313$ (tức giá trị trung bình). Những vị trí có điểm số cao hơn điểm chuẩn là vị trí có tính hợp lý, vị trí có điểm số thấp hơn điểm chuẩn thì có tính hợp lý thấp. Nghiên cứu tiếp tục đánh giá chi tiết hơn dựa vào độ lệch chuẩn $\sigma=0.103858$. Độ lệch chuẩn là mức độ ổn định của giá trị điểm của các ô quy hoạch xung quanh ngưỡng điểm chuẩn.

+ Nếu vị trí quy hoạch có điểm $<\mathrm{X}-\sigma(<$ $0.209455)$ thì được coi là rất không hợp lý.

+ Nếu vị trí quy hoạch có điểm từ $X=\sigma$ đến $\mathrm{X}$ (từ 0.103858 đến 0.313313 ) thì được coi là không hợp lý.

+ Nếu vị trí quy hoạch có điểm từ $\mathrm{X}$ đến $\mathrm{X}+$ $\sigma$ (từ 0.313313 đến 0.417171 ) thì được coi là hợp lý.

+ Nếu vị trí quy hoạch có điểm $>X+\sigma(>$ 0.417171) thì được coi là rất hợp lý.

Bảng 4: Phân tích mô tả dũ liệu giá trị hợp lý quy hoạch cum công nghiệp

\begin{tabular}{|c|c|c|c|c|}
\hline $\mathrm{N}$ & Minimum & Maximum & Mean & $\begin{array}{c}\text { Standard } \\
\text { Deviation }\end{array}$ \\
\hline 1480 & 0.067375 & 0.629467 & 0.313313 & 0.103858 \\
\hline
\end{tabular}

Qua đó, nghiên cứu đã xây dựng được sơ đồ thể hiện các vị trí thích hợp cho việc quy hoạch các cụm công nghiệp tại huyện Hoài đức với 4 nhóm vị trí: rất không hợp lý, không hợp lý, hợp lý và rất hợp lý.

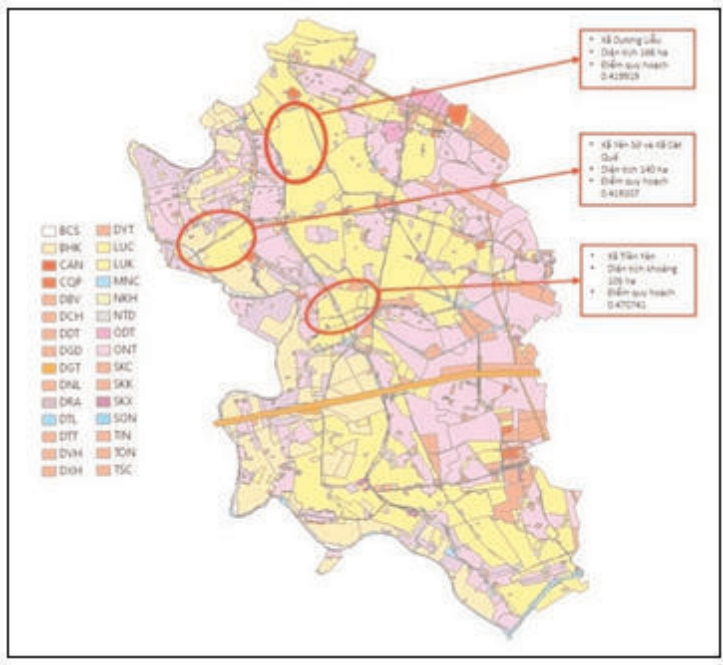

Hìn 7: So đồ vị trí hơp lý quy hoạch CCN tại huyện Hoài Đúc

Một số vị trí tiềm năng được xác định thể hiện trên sơ đồ như ở xã Dương Liễu, Cát Quế, Yên Sở, Tiền Yên đều thuộc những khu vực có điểm quy hoạch ở ngưỡng rất hợp lý. Các vị trí này đều có đặc điểm chung là quỹ đất đủ lớn, hiện trạng sử dụng đất hầu hết là đất nông nghiệp, gần đường giao thông chính, các cụm công nghiệp hiện có, các khu bãi rác, ... rất thuận tiện cho việc xây dựng và phát triển các cụm công nghiệp. Đồng thời, các vị trí hợp lý về mặt không gian sẽ giảm thiểu được ô nhiễm tới cuộc sống của người dân tại huyện Hoài Đức, đảm bảo mục tiêu phát triển kinh tế và bảo vệ môi trường. 


\section{Kết luận}

Lựa chọn vị trí quy hoạch cụm công nghiệp là một vấn đề quan trọng vì có tác động trực tiếp đến kinh tế, xã hội và môi trường ở từng địa phương. Đặc biệt tại khu vực huyện Hoài Đức, nơi có đề án phát triển thành quận đến năm 2025 . Thông qua hệ thống thông tin (GIS) với chức năng xử lý dữ liệu không gian và kỹ thuật phân tích thứ bậc AHP kết hợp cùng lý thuyết mờ Fuzzy logic đã giúp giải quyết bài toán trên một cách hiệu quả. Lý thuyết mờ đã được ứng dụng đã giúp tăng cường tính chính xác trong việc đưa ra ý kiến của chuyên gia.

Dựa trên bộ tiêu chí được xây dựng thông qua quá trình tham khảo ý kiến chuyên gia và nghiên cứu tài liệu, nghiên cứu đã đưa ra được các vị trí hợp lý về mặt không gian của đất cụm công nghiệp. Theo kết quả nghiên cứu, các vị trí có điểm quy hoạch cao đều thỏa mãn các chỉ tiêu đưa ra. Nghiên cứu mang lại kết quả hữu ích hỗ trợ việc lập quy hoạch sử dụng đất giai đoạn 2021-2030 tại huyện Hoài Đức, thành phố Hà Nội.O

\section{Lò̀i cảm ơn}

Nghiên cứu này được tài trợ bởi Trường Đại học Khoa học Tự nhiên, Đại học Quốc gia Hà Nội trong đề tài mã số TN.20.10.

\section{Tài liệu tham khảo}

[1]. Bhanu Chander Balusa, Amit Kumar Gorai (2019), "Sensitivity analysis of fuzzy-analytic hierarchical process (FAHP) decision-making model in selection of underground metal mining method", Journal of Sustainable Mining, 18 (1), 8-17.

[2]. Ahmad Ghorbanpour Hamid Shahbandarzadeh (2011), "The Applying ISM/FANP Approach for Appropriate Location Selection of Health Centers", 4(4-2), pp 5-28.

[3]. Siamak Kheybari, Fariba Mahdi Rezaie, Hadis Farazmand (2020), “Analytic network process: An overview of applications", Applied Mathematics and Computation, 367, 124780.

[4]. Steven Kuba Nuhu, Zainuddin Abdul Manan, Sharifah Rafidah Wan Alwi, Mohd Nadzri Md Reba (2021), "Roles of geospatial technology in eco-industrial park site selection: State-of-the-art review", Journal of Cleaner Production, 309, 127361.

[5]. Nahid Rezaeiniya (2014), “Fuzzy ANP Approach for New Application: Greenhouse Location Selection; a Case in Iran", vol 8, pp 120.

[6]. Aleksandar Rikalovic, Ilija Cosic, Djordje Lazarevic (2014), "GIS Based Multicriteria Analysis for Industrial Site Selection”, Procedia Engineering, 69, 1054-1063.

[7]. Zadeh L. A (1965), "Fuzzy Sets", vol 8, pp 338-353.

[8]. Bộ Kế hoạch đầu tư (2020), "Tình hình phát triển KCN, KKT 9 tháng năm 2020”.

[9]. Chính phủ (2017), “Nghị định số 68/2017/NĐ-CP về quản lý, phát triển cum công nghiệp".

[10]. Trần Kim Ngọc, Nguyễn Văn Lợi, Phạm Duy Hưng, (2020), "Úng dụng phuoong pháp AHP, FAHP và GIS trong đánh giá sụ thich hợp loài quế bản địa ở Trà Bồng, Quảng Ngãi”, Tạp chi Khoa hoc Đại học Huế: Nông nghiẹp và Phát triển nông thôn.

[11]. Nguyễn Xuân Linh và nnk (2016), "Úng dụng phương pháp phân tích đa chỉ tiêu ISM/F-ANP và GIS trong lưa chọn vị trí quy hoạch bãi chôn lấp chất thải rắn sinh hoạt trên địa bàn huyện Hưng Hà, tỉnh Thái Bình".

[12]. UBND huyện Hoài Đức (2020), “Báo cáo kiểm kê đất đai huyện Hoài Đức năm 2019". O 


\section{Summary}

Application of GIS technology combining analytic hierarchy process and fuzzy logic in selection the location for the industrial cluster planning in Hoai Duc district, Ha Noi city

Vu Khac Hung, Dong Vu Ha, Duong Hoang Long, Tran Thi Van Anh, Tran Van Tuan

VNU University of Science, Vietnam National University, Hanoi

The process of industrialization and modernization has contributed to the strong development of our country's economy in recent years, especially the construction of industrial zones and clusters.. By the end of 2020, there were 968 industrial clusters established in the whole country [8]. However, it is still difficult to arrange locations for construction of industrial clusters in localities because it ensures both economic development and environmental protection. The number of industrial clusters with environmental protection measures and waste treatment works accounts for only about $19.3 \%$. From the point of view of land management planners, it is very important to choose the planning locations for objects vulnerable to the environment such as industrial parks. A combination of AHP method, Fuzzy logic theory and GIS technology, helps to determine the appropriate location and assess the reasonableness for the planned locations. The research was carried out in Hoai Duc district, a suburban district of Hanoi, where there are many industrial clusters and production villages. $\bigcirc$

\section{ÚNG DỤNG CÔNG NGHÊ THÔNG TIN.....}

(Tiếp theo trang 34)

\section{Summary}

Apply information technology to assess single-ray depth measurement accuracy in seabed topography mapping

Nguyen Van Cuong, Agency of Seas and Islands Use Management

Nguyen Gia Trong, University of Mining and Geology

Nguyen The Hiep, University of Mining and Geology

Dang Viet Hoan, Vietnam's Naval Hydrographic and Oceanographic Department

Pham Thi Phuong Lien, Ministry of Natural Resources and Environment

When measuring depth to create a topographic map of the seabed, we cannot observe directly the topography of the measurement area. To properly represent the topography of the seabed, it is necessary to measure detailed points with many measuring points using echo sounding technology or a combination of some other underwater measuring technologies. However, there are many measuring points, besides the depth measuring lines, it is necessary to measure the test lines. After having the depth measurement data and test data, it is necessary to check the deviation between the depth determined by the test line and the depth determined by the depth gauge. We have learned the technical regulations on the evaluation of depth measurement results with the single-beam echo sounderometer to choose the algorithm as well as the programming language to build software for measuring measurement data. deep. The paper introduces the results of algorithm selection and depth measurement data testing software that have been built. The results of checking the single-ray echo depth measurement data, comparing and comparing with the results of the constructed works, the software meets the requirement of checking the depth measurement data with the single-beam echo sounding apparatus. $\bigcirc$ 